\title{
BMJ Open Growth data of underprivileged children living in rural areas of Chin State, Burma/Myanmar, compared to the WHO reference growth standards: an observational study
}

\author{
Malin Prenkert, ${ }^{1,2}$ Margareta Ehnfors ${ }^{2}$
}

To cite: Prenkert M, Ehnfors M. Growth data of underprivileged children living in rural areas of Chin State, Burma/Myanmar, compared to the WHO reference growth standards: an observational study. BMJ Open 2016;6:e009119. doi:10.1136/bmjopen-2015009119

\section{- Prepublication history} and additional material is available. To view please visit the journal (http://dx.doi.org/ 10.1136/bmjopen-2015009119)

Received 10 July 2015 Revised 4 December 2015 Accepted 7 December 2015

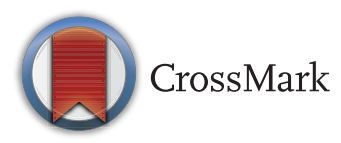

${ }^{1}$ Faculty of Medicine and Health, Centre for Health Care Sciences, Örebro University, Örebro, Sweden

${ }^{2}$ Faculty of Medicine and Health, School of Health and Medical Sciences, Örebro University, Örebro, Sweden

Correspondence to Dr Margareta Ehnfors; margareta.ehnfors@gmail.com

\section{ABSTRACT}

Objectives: To explore growth data (height-for-age, weight-for-age and BMI-for-age) of children living in poor socioeconomic conditions in rural areas of Chin State, Burma/Myanmar; and to compare these data with the growth and development z-score (GDZ) values for school-aged children and adolescents, provided by the WHO.

Setting: A support and educational programme, run by the Swedish association Chin Development and Research Society (CDRS), was carried out among underprivileged school-aged children, unable to attend school without economic and practical support, living in villages and remote areas in Chin State.

Participants: Community leaders who were well familiar with the citizens in the community identified children in need of this support. Other community members could also suggest or apply for this. The sample includes all participating children in the CDRS programme at the time of the data collection in six townships. The children were placed in host families, close to a suitable school. Two samples with a total of 639 children from 144 villages and remote areas were obtained:

1. Children in the CDRS Chin Programme (CCP) (20072010) comprised 558 children: $50 \%$ girls and boys.

2. Children in the Chin Society (CCS) (2010) comprised 81 children: $44 \%$ girls and $56 \%$ boys.

Primary outcome measures: Growth data.

Results: All growth data from both groups deviated significantly from the WHO standard references $(p \leq 0.001)$. The prevalence of stunting (height-for-age $\leq-2 \mathrm{SD}$ ) was $52 \%$ among girls and $68 \%$ among boys. High levels of wasting (weight-for-age $\leq-2 S D$ ) were found among girls $29 \%$ and boys $36 \%$ aged 5-10 years. In addition, severe thinness (BMI-for-age $\leq-2 \mathrm{SD}$ ) was found among girls $31 \%$ and boys $44 \%$, all results to be compared to the expected $2.27 \%$.

Conclusions: Many more than expected-according to the WHO reference values-in CCP and CCS suffered from stunting, wasting and thinness.

\section{Strengths and limitations of this study}

- Data were collected on underprivileged children living in villages and rural areas of Chin State, western Burma/Myanmar, in difficult environmental conditions, sometimes with no real roads in jungle-like areas. To the best of our knowledge, these children have not been studied previously.

- The WHO references for ages were compared to the year plus 6 months instead of the exact age, since the birthday was not known for all children. This may be a small classification bias of the growth indicators.

- No generalisation to the underlying population in Chin State or Burma/Myanmar may be carried out.

- Limited possibility to transfer the results: The CCP sample in this study comprised a selected group of underprivileged children who were part of a support and educational programme in Chin State, western Burma/Myanmar, organised from Sweden by the Chin Development and Research Society (CDRS). These children were offered a voluntary place in a host family, a temporary 'foster home'. The underlying cause for this was the inability, both economically and practically, of their own family to provide for their basic school education, and it is therefore reasonable to believe that these children were among the poorest in the society.

- The Children in the Chin Society sample is small due to the local situation. It comprises a convenience sample of children in ordinary families in the same society as CCP.

\section{INTRODUCTION}

Child growth data are an important indicator of general health and well-being. It is internationally agreed that stunting, undernutrition and thinness are recognised as the largest contributors to diseases in a 
population. ${ }^{1-3}$ It is also well documented that childhood stunting, defined as low height-for-age and thinness, defined as low body mass index (BMI)-for-age, are associated with long-term negative cognitive and physical consequences. ${ }^{2-4}$ Growth restricted children have shown significantly poorer performance in a wide range of $\operatorname{cog}$ nitive tests. ${ }^{5}{ }^{6}$ Suboptimal conditions for children are reported from many countries, mainly in Africa and Southeast Asia. Despite rich natural resources, Burma/ Myanmar is one of the poorest countries in the world in terms of its health situation, and there are widespread reports of human rights violations occurring under the former military junta. ${ }^{7}$ Following this, food security has been a long-standing concern, particularly in Chin State and the surrounding areas. Food insecurity is recognised as the main cause of under-nutrition. ${ }^{8}$

A support and educational programme in Chin State, western Burma/Myanmar, organised from Sweden by the Chin Development and Research Society (CDRS) and run by local fieldworkers, was carried out among underprivileged school-aged children. As part of the CDRS programme, these children were offered a voluntary place in a host family, a temporary 'foster home', situated in a city not always close to their biological home. The reasons for including the child comprised: the inability of the family to provide for the child's basic school education; one or both of the parents being dead; the home being broken; or the parents not having the practical or financial means to enrol the child in school. As part of the CDRS programme, a survey on growth, health, hygiene and nutritional status was conducted on all participating children. At the start of this study in 2007, the CDRS programme had been running for 4 years, accumulating more children every year. By 2013, more than 1600 Chin children were included. These children constitute the CCP group.

\section{RESEARCH BACKGROUND}

There is worldwide consensus that the concept of growth assessment is a usable measure for defining the health and nutritional status of a child. ${ }^{9}$ The WHO Child Growth Standards ${ }^{10}$ have been developed and state that children all over the world grow similarly when their health and care needs are met; the standards can therefore be used universally to assess children. This is regardless of ethnicity, socioeconomic status or food. ${ }^{10}{ }^{11}$ Field-testing of the WHO standards in four countries, comparing clinical assessment with the height-for-age, weight-for-age and BMI-for-age standards, concluded that the standards are clinically sound. ${ }^{12}$ The standards have been scrutinised and implemented widely. ${ }^{13}$

Our assumption was that the underprivileged children living in host families would have the same living conditions as other children in the same society. We therefore expected to find similar patterns of growth between these two groups. To explore this, we included a group of Chin children from ordinary families. However, owing to the political situation in Chin State at the time of the data collection (2010) with many limitations in the possibility of moving around, we were successful in getting only a small sample of participants for this Children in Chin Society (CCS) group $(n=81)$.

\section{OBJECTIVES}

Poor nutritional conditions may hamper growth and development among children and adolescents, and negatively influence their lives as adults. To the best of our knowledge, there is no published information regarding growth data of school-aged children living in Chin State, western Burma/Myanmar. We only found sparse data on children in Burma/Myanmar. Therefore, the objectives of this observational study were: (1) to explore growth data (ie, height-for-age, weight-for-age and BMI-for-age) of children living in poor environmental and socioeconomic conditions in villages and remote areas of Chin State who had been voluntarily moved to a foster family, and children from ordinary families in the same society, and (2) to compare these data with the growth and development z-score (GDZ) values for school-aged children and adolescents, provided by the WHO. ${ }^{14}$

\section{METHODS}

The study was planned in Sweden and conducted in Burma/Myanmar. Despite the problematic situation in Chin State, with an insufficient infrastructure and many barriers, the project was successfully completed. Three educational seminars with researchers and voluntary local fieldworkers were held outside Chin State in accordance with the rules of Burma/Myanmar at the time. These stated that foreigners could not freely enter the state. The fieldworkers sometimes had to travel for days under difficult environmental conditions to participate in these seminars. During the third seminar, preliminary data were presented as an attempt to validate the results. All families and children included were visited in their homes. According to the protocols of the CDRS programme, the trained fieldworkers were equipped with a questionnaire, a soft tape measure for height and a portable weighing scale. They also carried written instructions for hand hygiene principles and tablets of soap for the families. This was a key focus as hand hygiene is crucial in promoting health and preventing illness. This was also a way to implement the basic ambition of educating the families in hygiene routines.

\section{Participants}

The study has two sample groups: Children in CDRS Chin Programme (CCP) (2007-2010) and CCS (2010). CCP includes all children participating in the CDRS programme in villages and rural areas in Chin State. The CCS group includes children living in their own families, 
host families, in a smaller geographic area of Chin State. The selection was made from both urban and rural areas (CCP) and regardless of religious background.

\section{Sampling for CCP}

At the start of the support programme, community leaders in the six townships involved (including leaders from Christian churches and Buddhist temples), who were well familiar with the citizens in the community, identified underprivileged children in need of support and education. Other community members could also suggest or apply for this help. Through local coordinators of CDRS, the families got information and an invitation to participate and decide for themselves. Purposive sampling was used. These children were placed in host families, primarily relatives or friends, living close to a suitable school. Selection was from both urban and rural areas, regardless of the religious background (CCP $\mathrm{n}=558$ ).

\section{Sampling for CCS}

The local coordinators of CDRS were responsible in selecting the CCS children $(n=81)$. A convenience sampling was used. The children were identified as 'ordinary' children living in their own family, one of the host families.

A total of 639 children in the two samples were included after a few questionnaires had been excluded due to unclear notes. In CCP, all school-aged children, 5-19 years, enrolled in the educational project at the time of data collection, were included. CCP (2007-2010) comprises 558 children: $281(50 \%)$ girls and $277(50 \%)$ boys from 144 villages and rural areas. CCS (2010) comprises 81 children: $36(44 \%)$ girls and $45(56 \%)$ boys from 23 towns and villages. The children in CCP came from six of the nine Chin State townships: Hahka, Kanpetlet, Matupi, Mindat, Thantlang and Tedim. Those in CCS came from three townships: Kanpetlet, Matupi and Mindat.

The questionnaire developed contained basic health and demographic variables, such as age in years, sex, height and weight. In addition, self-descriptions of the meals of a normal day, and the child's eating, toileting and hand hygiene habits were surveyed (reported elsewhere). The questionnaire (see extra material) was mostly used in its English version and translated to Burmese and local languages for some geographical areas. In these cases, the fieldworkers spoke both languages and could explain the few questions that arose. One local field worker personally transported the completed questionnaire from CCP and CCS out of Chin State. All data were analysed in Sweden.

\section{Statistical methods}

The growth data: height-for-age, weight-for-age and BMI-for-age for both CCP and CCS were compared with corresponding reference values provided by the WHO. ${ }^{14}$ The reference values referring to the sixth month of each age were used for all children in each age group, since many did not know their exact age in months. The software used for the analyses was SPSS V.20 and Excel 14.

The $95 \%$ reference interval includes $95 \%$ of the central values and hence excludes $2.5 \%$ of the most extreme values at each end of a distribution. In normally distributed data, these are defined by the z-scores of $\pm 1.96 \mathrm{SD}$, commonly rounded up to $\pm 2 \mathrm{SD} .{ }^{15}$ The z-scores of $\pm 3 \mathrm{SD}$ define $99.7 \%$ of the central range of

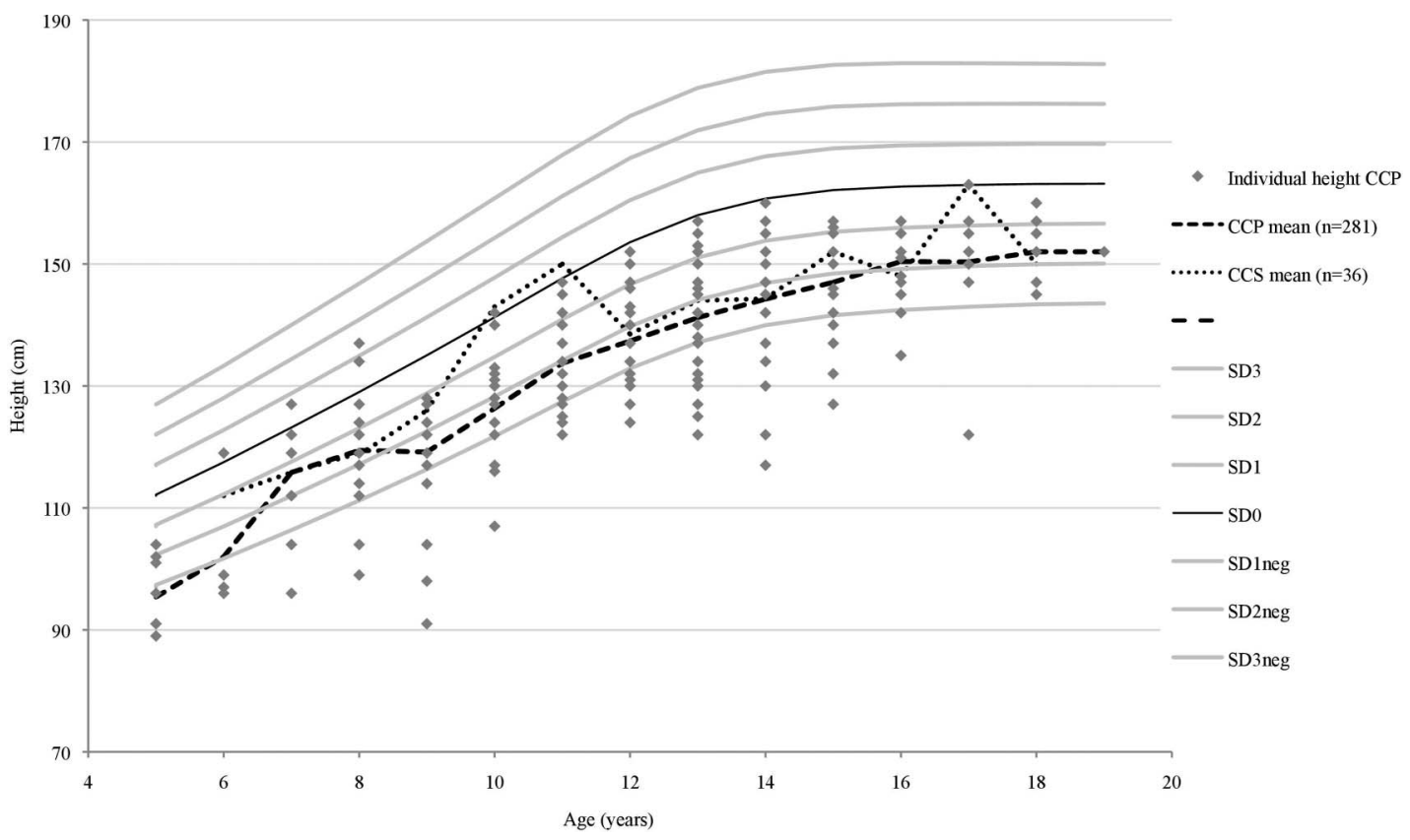

Figure 1 Height for age girls $5-19$ years $(n=317)$ and the WHO references (HAZ). 
Table 1 Height distribution of the 639 girls and boys in CCP and CCS, displayed by $\leq-3 S D, \leq-2 S D$ and $\leq 0$ SD

\begin{tabular}{|c|c|c|c|c|c|c|c|c|c|c|c|c|c|c|c|c|c|c|}
\hline \multirow{2}{*}{$\begin{array}{l}\text { Years } \\
\text { Age }\end{array}$} & \multicolumn{4}{|l|}{ CCP } & \multicolumn{4}{|l|}{ CCP } & \multicolumn{4}{|l|}{ CCS } & \multicolumn{4}{|l|}{ cCs } & \multicolumn{2}{|c|}{ Total 639} \\
\hline & $\begin{array}{l}\text { Girls, } \\
\text { n }\end{array}$ & $\begin{array}{l}\leq- \\
3 S D \\
\%\end{array}$ & $\begin{array}{l}\leq- \\
2 S D \\
\%\end{array}$ & $\begin{array}{l}\leq \\
\text { OSD, } \\
\%\end{array}$ & $\begin{array}{l}\text { Boys, } \\
\text { n }\end{array}$ & $\begin{array}{l}\leq- \\
3 S D, \\
\%\end{array}$ & $\begin{array}{l}\leq- \\
2 S D \\
\%\end{array}$ & $\begin{array}{l}\leq \\
\text { OSD, } \\
\%\end{array}$ & $\begin{array}{l}\text { Girls, } \\
\mathbf{n}\end{array}$ & $\begin{array}{l}\leq- \\
3 S D, \\
\%\end{array}$ & $\begin{array}{l}\leq- \\
2 S D \\
\%\end{array}$ & $\begin{array}{l}\leq \\
0 S D, \\
\%\end{array}$ & $\begin{array}{l}\text { Boys, } \\
\text { n }\end{array}$ & $\begin{array}{l}\leq- \\
3 S D \\
\%\end{array}$ & $\begin{array}{l}\leq- \\
2 S D \\
\%\end{array}$ & $\begin{array}{l}\leq \\
\text { OSD, } \\
\%\end{array}$ & $\begin{array}{l}\text { Girls, } \\
\text { n }\end{array}$ & $\begin{array}{l}\text { Boys, } \\
\text { n }\end{array}$ \\
\hline 5 & 8 & 75 & 88 & 100 & 5 & 40 & 80 & 100 & 0 & - & - & - & 0 & - & - & - & 8 & 5 \\
\hline 6 & 5 & 60 & 60 & 60 & 7 & 57 & 71 & 100 & 1 & 0 & 0 & 100 & 1 & 100 & 100 & 100 & 6 & 8 \\
\hline 7 & 11 & 18 & 36 & 100 & 13 & 46 & 54 & 92 & 0 & - & - & - & 5 & 20 & 60 & 80 & 11 & 18 \\
\hline 8 & 16 & 13 & 38 & 88 & 15 & 27 & 47 & 87 & 3 & 0 & 33 & 100 & 2 & 50 & 50 & 100 & 19 & 17 \\
\hline 9 & 25 & 16 & 64 & 100 & 23 & 4 & 39 & 96 & 4 & 25 & 50 & 75 & 3 & 33 & 33 & 100 & 29 & 26 \\
\hline 10 & 22 & 18 & 55 & 95 & 16 & 19 & 60 & 100 & 3 & 0 & 0 & 33 & 4 & 25 & 25 & 50 & 25 & 20 \\
\hline 11 & 26 & 39 & 65 & 96 & 36 & 31 & 67 & 94 & 1 & 0 & 0 & 0 & 2 & 0 & 15 & 100 & 27 & 38 \\
\hline 12 & 27 & 30 & 63 & 100 & 20 & 30 & 80 & 100 & 4 & 25 & 50 & 100 & 7 & 43 & 86 & 100 & 31 & 27 \\
\hline 13 & 33 & 33 & 51 & 100 & 26 & 19 & 62 & 96 & 5 & 20 & 60 & 80 & 3 & 0 & 0 & 100 & 38 & 29 \\
\hline 14 & 29 & 28 & 52 & 100 & 36 & 31 & 75 & 97 & 7 & 29 & 57 & 100 & 4 & 50 & 75 & 75 & 36 & 40 \\
\hline 15 & 33 & 30 & 45 & 100 & 25 & 60 & 72 & 96 & 3 & 33 & 33 & 100 & 7 & 28 & 86 & 100 & 36 & 32 \\
\hline 16 & 20 & 5 & 35 & 100 & 20 & 46 & 75 & 100 & 3 & 33 & 67 & 100 & 6 & 17 & 67 & 100 & 23 & 26 \\
\hline 17 & 15 & 6 & 40 & 100 & 20 & 55 & 85 & 100 & 1 & 0 & 0 & 100 & 0 & - & - & - & 16 & 20 \\
\hline 18 & 10 & 0 & 30 & 100 & 11 & 9 & 73 & 100 & 1 & 0 & 100 & 100 & 1 & 100 & 100 & 100 & 11 & 12 \\
\hline 19 & 1 & 0 & 0 & 100 & 4 & 25 & 75 & 100 & 0 & - & - & - & 0 & - & - & - & 1 & 4 \\
\hline Total & 281 & 25 & 52 & 98 & 277 & 32 & 68 & 97 & 36 & 19 & 44 & 86 & 45 & 31 & 62 & 91 & 317 & 322 \\
\hline Range, \% & & $0-75$ & $0-88$ & $\begin{array}{l}60- \\
100\end{array}$ & & $4-60$ & 39-85 & $\begin{array}{l}87- \\
100\end{array}$ & & $0-33$ & $0-100$ & $\begin{array}{l}0- \\
100\end{array}$ & & $0-100$ & $0-100$ & $\begin{array}{l}50- \\
100\end{array}$ & & \\
\hline
\end{tabular}

CCP, Children in the CDRS Chin Programme; CCS, Children in the Chin Society. 
Table 2 Bonferroni (B) corrected $\mathrm{p}$ values-test of differences to WHO-references

\begin{tabular}{|c|c|c|c|c|c|c|c|c|c|c|c|c|c|}
\hline & & \multicolumn{3}{|c|}{$\leq-S D 3,0.1 \%$} & \multicolumn{3}{|c|}{$\leq-S D 2,2.3 \%$} & \multicolumn{3}{|c|}{$\leq-\operatorname{SD~} 1,15.9 \%$} & \multicolumn{3}{|c|}{ SD $0,50 \%$} \\
\hline & $\mathbf{n}$ & $\mathbf{n}$ & Per cent & $\begin{array}{c}\text { B } \\
\text { p Value }\end{array}$ & $\mathbf{n}$ & Per cent & $\begin{array}{c}\text { B } \\
\text { p Value }\end{array}$ & $\mathbf{n}$ & Per cent & $\begin{array}{c}\text { B } \\
p \text { Value }\end{array}$ & $\mathbf{n}$ & Per cent & $\begin{array}{c}\text { B } \\
\text { p Value }\end{array}$ \\
\hline \multicolumn{14}{|l|}{ Height } \\
\hline CCP Girls & 281 & 70 & 25 & 0.000 & 145 & 52 & 0.000 & 240 & 85 & 0.000 & 275 & 98 & 0.000 \\
\hline CCS Girls & 36 & 7 & 19 & 0.000 & 16 & 44 & 0.000 & 25 & 69 & 0.000 & 31 & 86 & 0.001 \\
\hline All girls & 317 & & & & & & & & & & & & \\
\hline CCP Boys & 277 & 90 & 32 & 0.000 & 187 & 68 & 0.000 & 249 & 90 & 0.000 & 268 & 97 & 0.000 \\
\hline CCS Boys & 45 & 14 & 31 & 0.000 & 28 & 62 & 0.000 & 39 & 87 & 0.000 & 41 & 91 & 0.000 \\
\hline All boys & 322 & & & & & & & & & & & & \\
\hline Height total & 639 & & & & & & & & & & & & \\
\hline \multicolumn{14}{|l|}{ Weight } \\
\hline CCP Girls $\leq 10$ years, & 87 & 12 & 14 & 0.000 & 25 & 29 & 0.000 & 62 & 71 & 0.000 & 78 & 90 & 0.000 \\
\hline CCS Girls $\leq 10$ years, & 11 & 3 & 27 & 0.000 & 4 & 36 & 0.000 & 7 & 64 & 0.001 & 7 & 64 & 1.000 \\
\hline All girls $\leq 10$ years & 98 & & & & & & & & & & & & \\
\hline CCP Boys $\leq 10$ years, & 79 & 15 & 19 & 0.000 & 35 & 44 & 0.000 & 53 & 67 & 0.000 & 65 & 82 & 0.000 \\
\hline CCS Boys $\leq 10$ years, & 15 & 3 & 20 & 0.000 & 6 & 40 & 0.000 & 11 & 73 & 0.000 & 14 & 93 & 0.057 \\
\hline All boys $\leq 10$ years & 94 & & & & & & & & & & & & \\
\hline Weight total $\leq 10$ years & 192 & & & & & & & & & & & & \\
\hline \multicolumn{14}{|l|}{$\mathrm{BMI}$} \\
\hline CCP Girls & 281 & 26 & 9 & 0.000 & 59 & 21 & 0.000 & 108 & 38 & 0.000 & 176 & 63 & 0.002 \\
\hline CCS Girls & 36 & 5 & 14 & 0.000 & 11 & 31 & 0.000 & 16 & 44 & 0.000 & 24 & 67 & 1.000 \\
\hline All girls & 317 & & & & & & & & & & & & \\
\hline CCP Boys & 277 & 21 & 8 & 0.000 & 52 & 19 & 0.000 & 113 & 41 & 0.000 & 175 & 63 & 0.001 \\
\hline CCS Boys & 45 & 13 & 29 & 0.000 & 20 & 44 & 0.000 & 25 & 56 & 0.000 & 35 & 78 & 0.014 \\
\hline All boys & 322 & & & & & & & & & & & & \\
\hline Children total & 639 & & & & & & & & & & & & \\
\hline
\end{tabular}




\begin{tabular}{|c|c|c|c|c|}
\hline Variable and sex & $\leq 3 \mathrm{SD}$ & $\leq 2 \mathrm{SD}$ & $\leq 1 \mathrm{SD}$ & $\leq$ OSD \\
\hline \multicolumn{5}{|l|}{ Height } \\
\hline \multicolumn{5}{|l|}{ Girls } \\
\hline $\mathrm{CCP} / \mathrm{CCS}$ & 1000 & 1000 & 1000 & $p=002$ \\
\hline \multicolumn{5}{|l|}{ Boys } \\
\hline CCP/CCS & 1000 & 1000 & 1000 & 1000 \\
\hline \multicolumn{5}{|l|}{ Weight } \\
\hline \multicolumn{5}{|l|}{ Girls } \\
\hline CCP/CCS & 1000 & 1000 & 1000 & 1000 \\
\hline \multicolumn{5}{|l|}{ Boys } \\
\hline CCP/CCS & 1000 & 1000 & 1000 & 1000 \\
\hline \multicolumn{5}{|l|}{ BMI } \\
\hline \multicolumn{5}{|l|}{ Girls } \\
\hline $\begin{array}{l}\mathrm{CCP} / \mathrm{CCS} \\
\text { Boys }\end{array}$ & 1000 & 1000 & 1000 & 1000 \\
\hline CCP/CCS & $\mathrm{p}=0001$ & $\mathrm{p}=0009$ & 1000 & 1000 \\
\hline
\end{tabular}

Test of differences between the samples CCP $(n=558)$ and CCS. $(n=81)$ at $\leq 3 S D, \leq 2 S D, \leq 1 S D$ and $\leq 0 S D$.

$\mathrm{BMI}$, body mass index; CCP, Children in the CDRS Chin

Programme; CCS, Children in the Chin Society.

values excluding the $0.13 \%$ most extreme values at each end of the distribution. The following definitions, based on the WHO standards for $95 \%$ reference limits, ${ }^{16}$ were used for comparison: stunting defined as the height-for-age z-score (HAZ) $\leq-2 \mathrm{SD}$; underweight as the weight-for-age z-score (WAZ) $\leq-2 \mathrm{SD}$ and thinness as the BMI-for-age $z$-score (BMIAZ) $\leq-2$ SD. ${ }^{17-19}$

The individual data only from CCP $(n=558)$ were plotted in the WHO reference charts displaying the z-score curves against gender, age in years and the three growth variables. The age-specific frequencies and proportions of girls and boys with variable values equal to or below the z-scores of $0 \mathrm{SD}$, that is, mean values $\leq-2 \mathrm{SD}$ and $\leq-3 S D$, were calculated. Bonferroni corrected $p$ values were calculated. This is a simple correction of the $\mathrm{p}$ value to adjust for multiple tests. Multiplying by the number of calculated $\mathrm{p}$ values (in our case 36 tests) gives a Bonferroni corrected $\mathrm{p}$ value. A $\mathrm{p}$ value of $<0.05$ was considered statistically significant.

\section{ETHICAL CONSIDERATIONS}

The children in CCP were participants in the CDRS programme, while the CCS children were living in their own families, which were host families in the programme. The data collection was part of the support programme, which they all voluntarily applied for or agreed to participate in. All families were visited in their homes as part of the programme. The parents and children orally agreed to participate in this project after receiving additional verbal information.

Three seminars with the fieldworkers and the researchers were conducted inside Burma/Myanmar but outside Chin State, since foreigners were not allowed into Chin State due to the political situation at the time. For the same reason, it was not possible to get an ethical review of the project in Burma/Myanmar. Ethical aspects of this public health study were discussed in a seminar at Örebro University in Sweden. No sensitive data were collected. Data collection was assessed as having no or minimal risk of harm or violation of privacy or human rights for any of the participating families or children. All results are published on a group level and no individuals can be identified. The ambition in the project was to use good research practice.

\section{RESULTS}

There are two samples: the CCP who were underprivileged children participating in the CDRS-support programme; and CCS who were ordinary children in host families in the CDRS-programme. The total of 639 children in the two samples came from six of the nine townships in Chin State. They were school-aged, between 5 and 19 years, and included altogether 317 girls and 322 boys $(50 \%$ per group). The sex and age distributions of CCP (2007-2010) and CCS (2010) are reported in

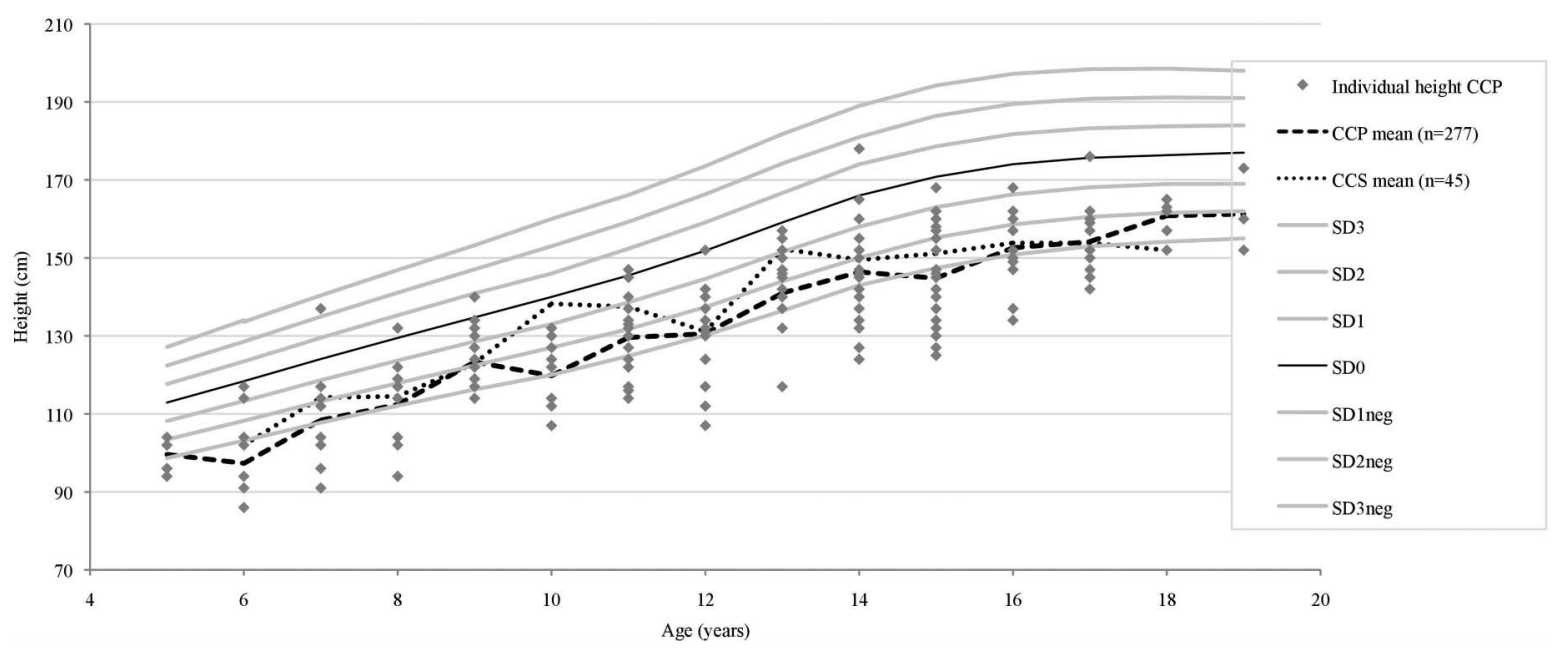

Figure 2 Height for age boys $5-19$ years $(n=322)$ and the WHO references (HAZ). 


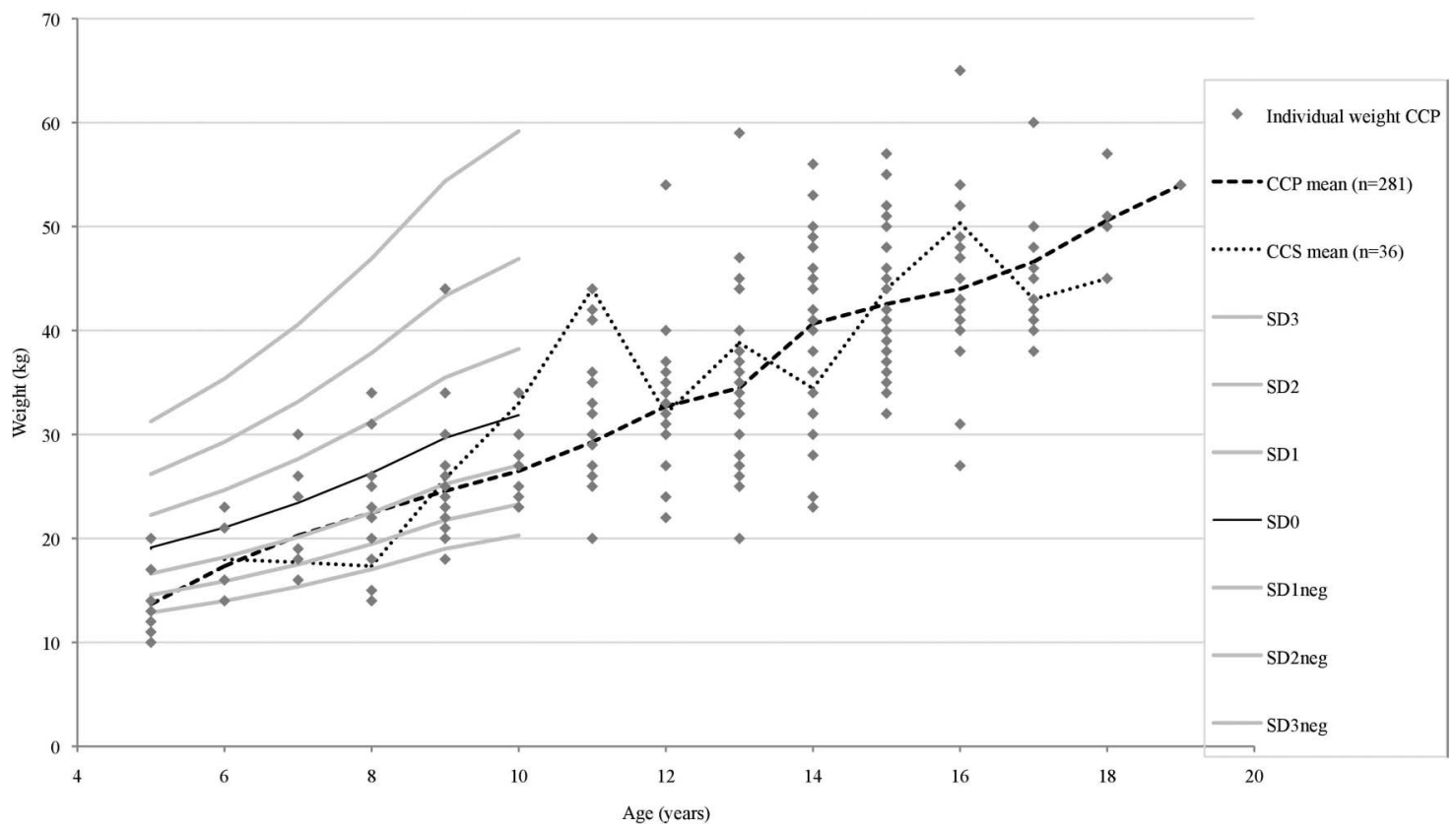

Figure 3 Weight for age girls $5-19$ years $(n=317)$, and the WHO references (WAZ) age 5-10 years.

tables. The mean values are given for the two samples CCP and CCS. For CCP; data are plotted individually into the WHO standard curves for height-for-age, weight-for-age and BMI-for-age.

\section{Height-for-age}

Height-for-age girls

The distribution of height-for-age in the 281 girls in CCP, compared to the WHO child growth standards HAZ (figure 1), showed that $98 \%$ were at or below the WHO reference mean height (0SD) compared to an expected $50 \%$. Among girls, $86 \% \quad(n=36)$ in CCS were at or below 0SD. The proportion of girls with a height-for-age $\leq-2 \mathrm{SD}$ was $52 \%$ in CCP and $44 \%$ in CCS, compared to an expected $2.27 \%$. The proportion of girls with a height-for-age $\leq-3 \mathrm{SD}$ was $25 \%$ in CCP and $19 \%$ in CCS, compared to an expected $0.13 \%$ (table 1).

All findings on height-for-age among girls significantly deviated $(\mathrm{p} \leq 0.001)$ from the WHO standards (table 2). Comparing CCP girls' height-for-age to that of CCS girls showed no statistically significant difference $(p=N S)$ except for CCS $\leq 0 \mathrm{SD}$ ( $\mathrm{p}=0.021$; table 3 ).

\section{Height-for-age boys}

The distribution of height-for-age, compared to the WHO child growth standards HAZ, showed that $97 \%$ $(n=277)$ in CCP and $91 \% \quad(n=45)$ in CCS were at or below the WHO reference mean height (OSD; figure 2). The proportion of boys with a height-for-age $\leq-2 \mathrm{SD}$ was $68 \%$ in CCP and $62 \%$ in CCS. The proportion of boys with a height-for-age $\leq-3 \mathrm{SD}$ was $32 \%$ in CCP and $31 \%$ in CCS (table 1).

All findings on height-for-age among boys significantly deviated $(\mathrm{p} \leq 0.001)$ from the WHO standards (table 2$)$.
Comparing CCP boys' height-for-age to that of CCS boys showed no statistically significant difference $(p=N S$; table 3).

\section{Weight-for-age}

The WHO child growth references (WAZ) are only available for the ages $5-10$ years.

\section{Weight-for-age girls}

The distribution of weight-for-age girls aged 5-10 years, compared to the WHO child growth standards WAZ, showed that $90 \% \quad(n=87)$ in CCP and $64 \% \quad(n=11)$ in CCS were at or below the WHO reference mean weight (0SD; figure 3 ). The proportion of girls aged 5-10 years with a weight-for-age $\leq-2 \mathrm{SD}$ was $29 \%$ in CCP and $36 \%$ in CCS. The proportion of girls aged 5-10 years with a weight-for-age $\leq-3 \mathrm{SD}$ was $14 \%$ in CCP and $27 \%$ in CCS (table 4).

All findings on weight-for-age among girls aged 510 years significantly deviated $(\mathrm{p} \leq 0.001)$ from the WHO standards, except CCS $\leq$ OSD ( $\mathrm{p}=\mathrm{NS}$; table 2 ).

Comparing CCP girls' weight-for-age to that of CCS girls showed no statistically significant difference ( $p=N S$; table 3).

\section{Weight-for-age boys}

The distribution of weight-for-age boys aged 5-10 years, compared to the WHO child growth standards WAZ, showed that $82 \%(n=79)$ in CCP and $93 \%(n=15)$ in CCS were at or below the WHO reference mean height (0SD; figure 4 ). The proportion of boys aged $5-10$ years with a weight-for-age $\leq-2 \mathrm{SD}$ was $44 \%$ in CCP and $40 \%$ in CCS. The proportion of boys aged 5-10 years with a weight-for-age $\leq-3$ SD was $19 \%$ in CCP and $20 \%$ in CCS (table 4). 


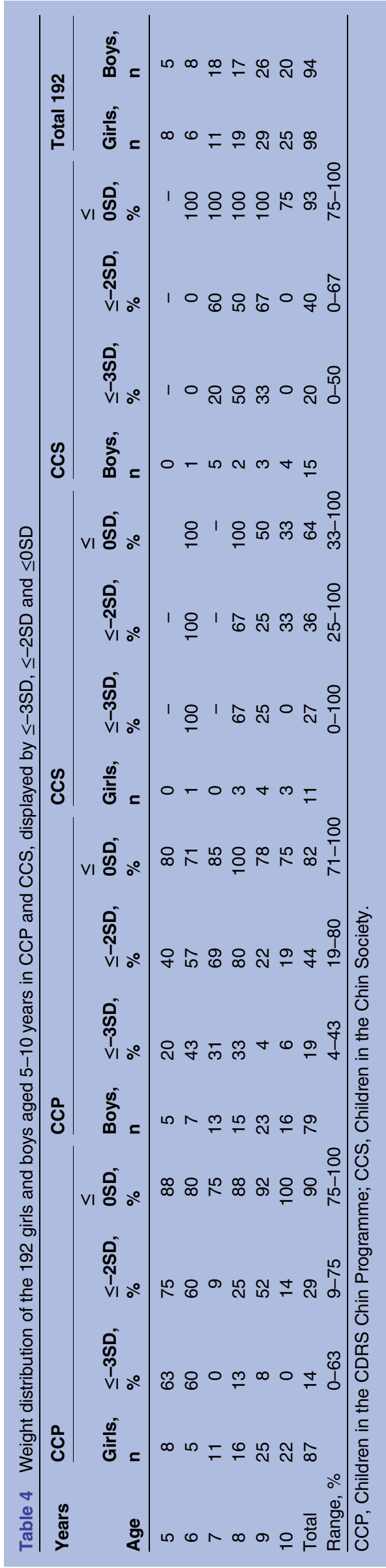

All findings on weight-for-age among boys aged 510 years significantly deviated $(\mathrm{p} \leq 0.001)$ from the WHO standards, except CCS $\leq$ OSD ( $p=N S$; table 2 ).

Comparing CCP boys' weight-for-age to that of CCS boys showed no statistically significant difference $(p=N S$; table 3).

\section{BMI-for-age}

BMl-for-age girls

The distribution of BMI-for-age girls, compared to the WHO child growth standards BMIAZ, showed that $63 \%$ $(n=281)$ in CCP and $67 \% \quad(n=36)$ in CCS were at or below the WHO reference mean BMI (0SD; figure 5). The proportion of girls with a BMI-for-age $\leq-2 \mathrm{SD}$ was $21 \%$ in CCP and $31 \%$ in CCS. The proportion of girls with a BMI-for-age $\leq-3 \mathrm{SD}$ was $9 \%$ in CCP and $14 \%$ in CCS (table 5).

All findings on BMI-for-age among girls significantly deviated $(p \leq 0.001)$ from the WHO standards, except CCS $\leq 0$ SD $(p=N S)$ (table 2).

Comparing CCP girls' BMI-for-age to that of CCS girls showed no statistically significant difference ( $p=N S$; table 3).

\section{BMI-for-age boys}

The distribution of BMI-for-age boys, compared to the WHO child growth standards BMIAZ, showed that $63 \%$ $(n=277)$ of boys in CCP and 79\% $(n=45)$ in CCS were at or below the WHO reference mean BMI (0SD; figure $6)$. The proportion of boys with a BMI-for-age $\leq-2 \mathrm{SD}$ was $19 \%$ in CCP and $44 \%$ in CCS. The proportion of boys with a BMI-for-age $\leq-3 \mathrm{SD}$ was $8 \%$ in CCP and $29 \%$ in CCS (table 5).

All findings on BMI-for-age in boys significantly deviated $(\mathrm{p} \leq 0.001)$ from the WHO standards (table 2$)$.

Comparing CCP boys' BMI-for-age to that of CCS boys showed no statistically significant difference $(p=N S)$ except for CCS $\leq-2 \mathrm{SD}(\mathrm{p}=0.009)$ and $\leq-3 \mathrm{SD}(\mathrm{p}=0.001$; table 3).

\section{Differences between girls and boys in the three variables}

There were no statistical differences between girls and boys in the three variables studied except for girls' height in one subgroup; girls were shorter than boys at $\leq \mathrm{SD} 2$, where a statistical assured difference showed that CCP girls were shorter than CCP boys $(p=0.00013$; Bonferroni corrected $p$ value 0.00466).

\section{DISCUSSION}

\section{Key results}

The results showed that the growth data of these underprivileged children living in Chin State deviated considerably from international references for both girls and boys in the three variables studied: height-for-age, weight-for-age and BMI-for-age. On the basis of international references, many more children than expected suffered from stunting, wasting and thinness. The pattern was the same for both 


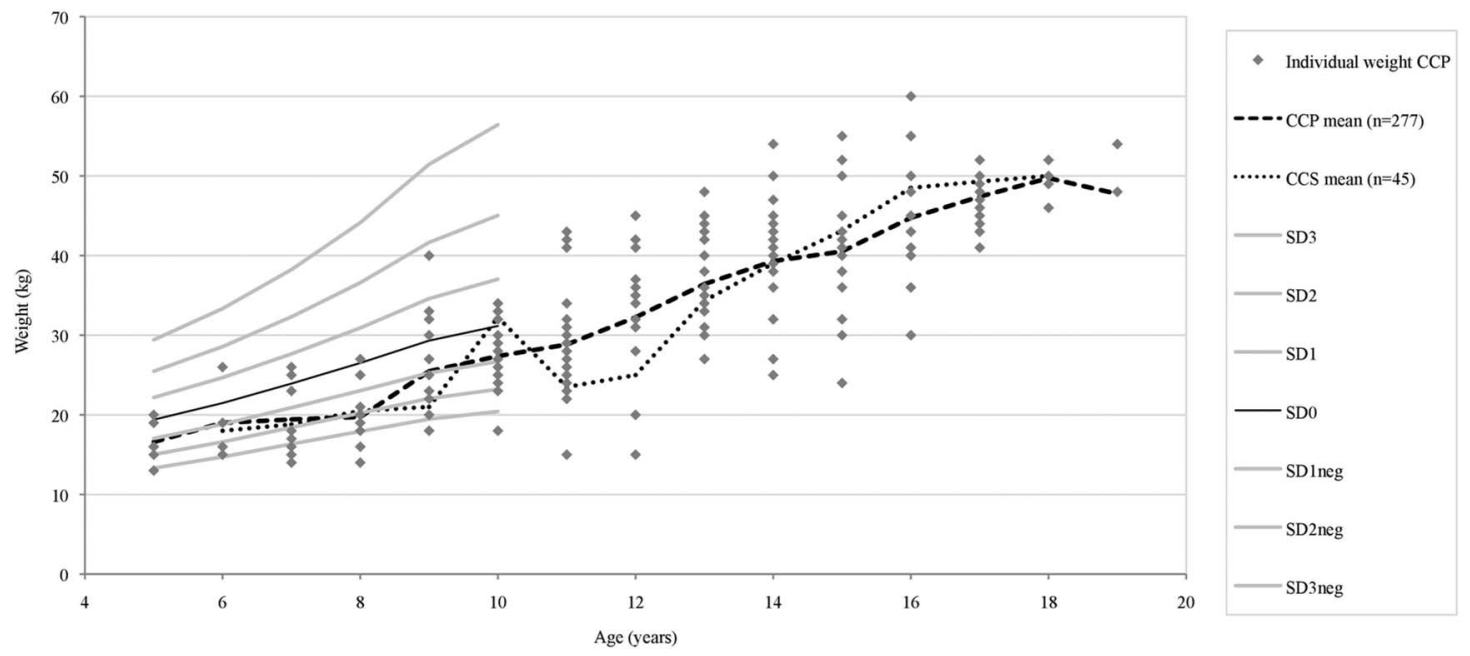

Figure 4 Weight for age boys 5-19 years $(n=322)$ and the WHO references (WAZ), age $5-10$ years.

CCP (2007-2010) and CCS (2010) samples. The children in the educational project were all living in a host family to be able to attend school. However, the CCS children, those living in a normal situation in their own homes, also showed similar problematic growth data. This was statistically confirmed.

The mean weight-for-age in the empirical data for both girls and boys followed the WHO standard references close to the level of $\leq-1$ SD for ages 5-10 years. For ages 11-19 years, which have no WHO standard references, one can extrapolate to approximately the same slope, that is, the mean of the empirical data remained close to $\leq-1 \mathrm{SD}$.

The BMI results deviated less from the international standards among both boys and girls than the other two variables studied. No gender difference was found. These BMI results were to be expected since the children of both sexes were both thin and short.
Across both CCP and CCS, very many children suffered from severe acute and chronic malnutrition that may result in substantial morbidity, loss of quality of life and even imply long-term developmental problems and educational underachievement. This may diminish their ability to work and thereby reduces the potential for national development. ${ }^{20}$

\section{Research in context}

The analysis of selected papers from repeated literature searches on growth data, children and nutrition in the scientific literature revealed similar results reported from other parts of East Asia ${ }^{21-27}$ (see online supplementary table S1).

The prevalence of stunting (height-for-age $\leq-2 \mathrm{SD}$ ) among girls (52\%) and boys (68\%) in our selected group of Chin children was considerably higher compared to findings in other countries and to the expected $2.27 \%$.

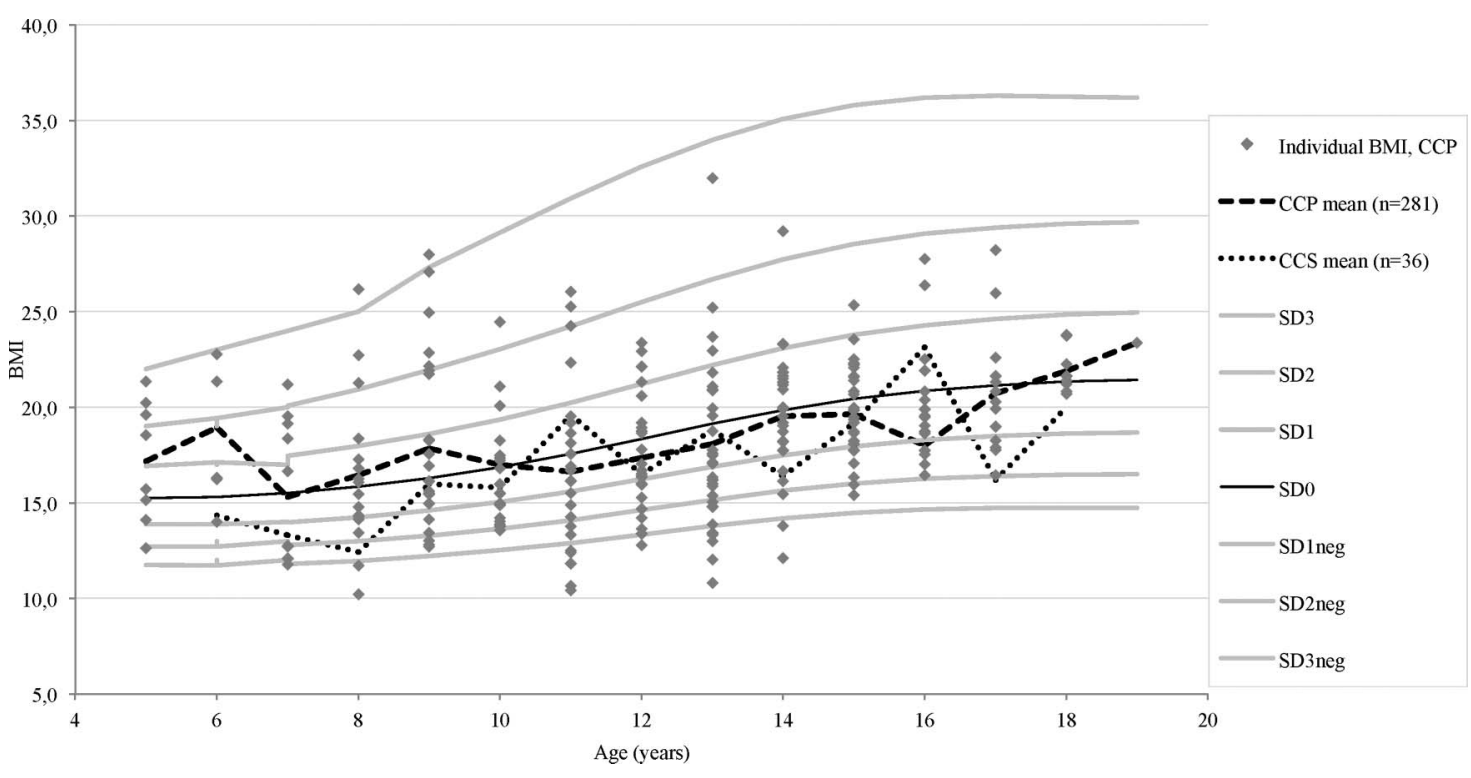

Figure 5 BMl girls aged $5-19$ years $(n=317)$ and the WHO references. BMI, body mass index. 
Table 5 BMI distribution of the 639 girls and boys in CCP and CCS, displayed by $\leq-3 S D, \leq-2 S D$ and $\leq 0 S D$

\begin{tabular}{|c|c|c|c|c|c|c|c|c|c|c|c|c|c|c|c|c|c|c|}
\hline \multirow{2}{*}{$\begin{array}{l}\text { Years } \\
\text { Age }\end{array}$} & \multicolumn{4}{|l|}{ CCP } & \multicolumn{4}{|l|}{ CCP } & \multicolumn{4}{|l|}{ Ccs } & \multicolumn{4}{|l|}{ CCS } & \multicolumn{2}{|c|}{ Total 639} \\
\hline & $\begin{array}{l}\text { Girls, } \\
\text { n }\end{array}$ & $\begin{array}{l}\leq- \\
3 S D \\
\%\end{array}$ & $\begin{array}{l}\leq- \\
2 S D \\
\%\end{array}$ & $\begin{array}{l}\leq \\
\text { OSD, } \\
\%\end{array}$ & $\begin{array}{l}\text { Boys, } \\
\text { n }\end{array}$ & $\begin{array}{l}\leq- \\
3 S D \\
\%\end{array}$ & $\begin{array}{l}\leq- \\
2 S D \\
\%\end{array}$ & $\begin{array}{l}\leq \\
\text { OSD, } \\
\%\end{array}$ & $\begin{array}{l}\text { Girls, } \\
\text { n }\end{array}$ & $\begin{array}{l}\leq- \\
3 S D \\
\%\end{array}$ & $\begin{array}{l}\leq- \\
2 S D \\
\%\end{array}$ & $\begin{array}{l}\leq \\
\text { OSD, } \\
\%\end{array}$ & $\begin{array}{l}\text { Boys, } \\
\text { n }\end{array}$ & $\begin{array}{l}\leq- \\
3 S D \\
\%\end{array}$ & $\begin{array}{l}\leq- \\
2 S D \\
\%\end{array}$ & $\begin{array}{l}\leq \\
\text { OSD, } \\
\%\end{array}$ & $\begin{array}{l}\text { Girls, } \\
\text { n }\end{array}$ & $\begin{array}{l}\text { Boys, } \\
\text { n }\end{array}$ \\
\hline 5 & 8 & 0 & 13 & 25 & 5 & 0 & 0 & 40 & 0 & - & - & - & 0 & - & - & - & 8 & 5 \\
\hline 6 & 5 & 20 & 20 & 20 & 7 & 0 & 0 & 14 & 1 & 0 & 0 & 100 & 1 & 0 & 0 & 0 & 6 & 8 \\
\hline 7 & 11 & 36 & 54 & 54 & 13 & 15 & 31 & 54 & 0 & - & - & - & 5 & 20 & 40 & 80 & 11 & 18 \\
\hline 8 & 16 & 13 & 19 & 63 & 15 & 7 & 47 & 73 & 3 & 67 & 67 & 100 & 2 & 0 & 0 & 100 & 19 & 17 \\
\hline 9 & 25 & 0 & 10 & 56 & 23 & 9 & 30 & 70 & 4 & 25 & 25 & 25 & 3 & 67 & 67 & 67 & 29 & 26 \\
\hline 10 & 22 & 0 & 27 & 82 & 16 & 0 & 6 & 50 & 3 & 33 & 33 & 67 & 4 & 25 & 25 & 50 & 25 & 20 \\
\hline 11 & 26 & 27 & 35 & 73 & 36 & 11 & 14 & 58 & 1 & 0 & 0 & 0 & 2 & 100 & 100 & 100 & 27 & 38 \\
\hline 12 & 27 & 11 & 30 & 63 & 20 & 10 & 10 & 60 & 4 & 0 & 50 & 75 & 7 & 57 & 86 & 100 & 31 & 27 \\
\hline 13 & 33 & 21 & 36 & 70 & 26 & 4 & 8 & 62 & 5 & 0 & 0 & 60 & 3 & 33 & 100 & 100 & 38 & 29 \\
\hline 14 & 29 & 7 & 14 & 55 & 36 & 8 & 33 & 56 & 7 & 14 & 57 & 100 & 4 & 25 & 50 & 75 & 36 & 40 \\
\hline 15 & 33 & 0 & 9 & 64 & 25 & 12 & 16 & 64 & 3 & 0 & 33 & 67 & 7 & 14 & 14 & 86 & 36 & 32 \\
\hline 16 & 20 & 0 & 5 & 75 & 20 & 5 & 25 & 75 & 3 & 0 & 0 & 33 & 6 & 0 & 17 & 67 & 23 & 26 \\
\hline 17 & 15 & 0 & 7 & 67 & 20 & 5 & 5 & 75 & 1 & 0 & 0 & 0 & 0 & - & - & - & 16 & 20 \\
\hline 18 & 10 & 0 & 0 & 40 & 11 & 0 & 0 & 100 & 1 & 0 & 0 & 100 & 1 & 0 & 0 & 0 & 11 & 12 \\
\hline 19 & 1 & 0 & 0 & 0 & 4 & 25 & 50 & 100 & 0 & - & - & - & 0 & - & - & - & 1 & 4 \\
\hline Total & 281 & 9 & 21 & 63 & 277 & 8 & 19 & 63 & 36 & 14 & 31 & 67 & 45 & 29 & 44 & 79 & 317 & 322 \\
\hline Range \% & & $0-36$ & $0-54$ & $0-82$ & & $0-25$ & $0-50$ & $14-100$ & & $0-67$ & $0-67$ & $0-100$ & & $0-100$ & $0-100$ & $0-100$ & & \\
\hline
\end{tabular}

BMI, body mass index; CCP, Children in the CDRS Chin Programme; CCS, Children in the Chin Society. 


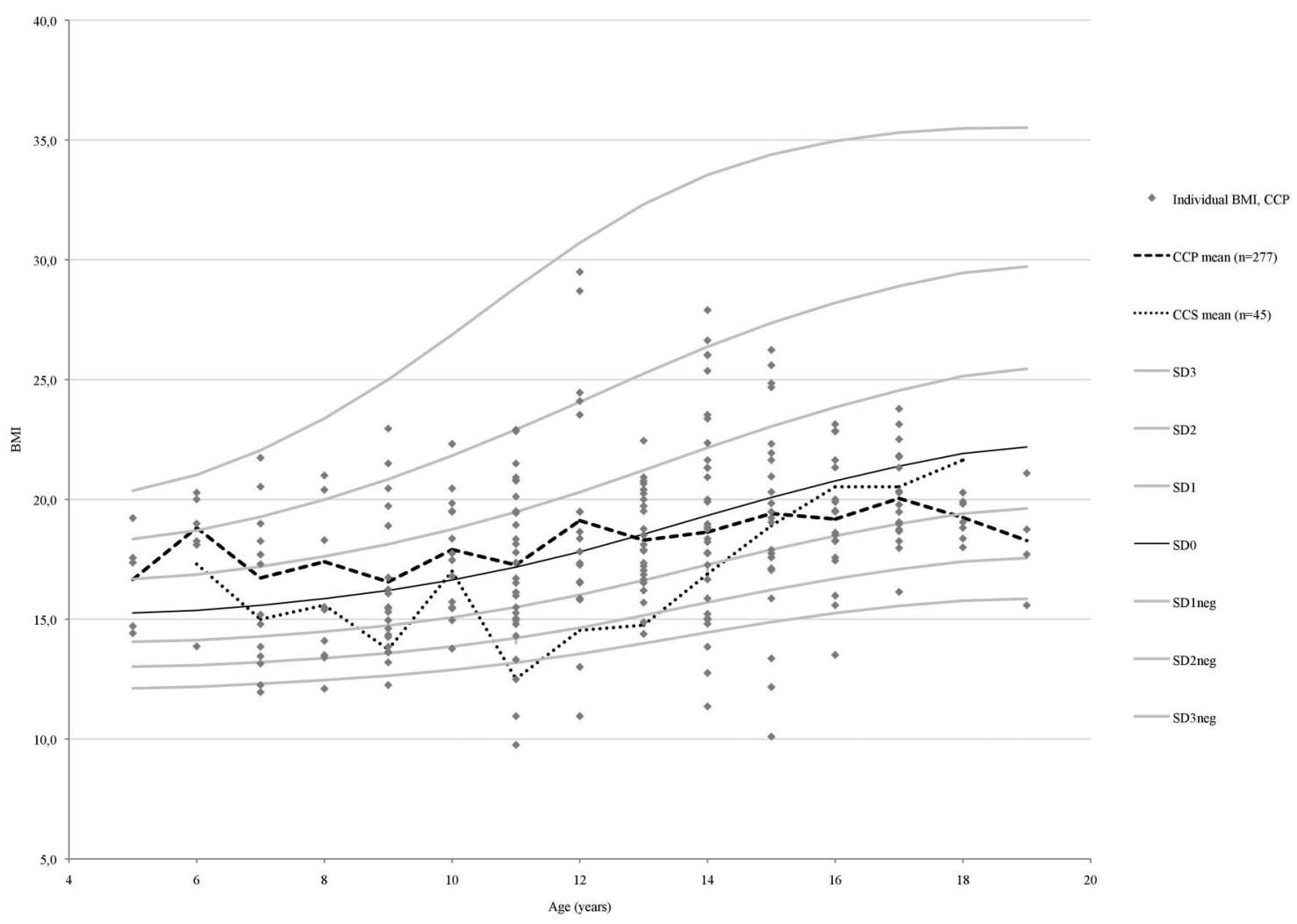

Figure 6 BMI boys aged $5-19$ years $(n=322)$ and the WHO references. BMI, body mass index.

However, published data from other areas report high levels of stunting as well; in North Korea (age $<7$ ), stunting was found in $39 \%$ of the girls and $40 \%$ of the boys, ${ }^{28}$ and in India $28 \%$ of the girls and $29 \%$ of the boys were stunting $^{29}$ according to the height-for-age $\leq-2$ SD limit.

High levels of wasting (weight-for-age $\leq-2 \mathrm{SD}$ ) were found for both girls $(29 \%)$ and boys $(36 \%)$ aged $5-10$ years in the present study. Similar situations of wasting were also reported from Nepal with $46 \%$ girls and $53 \%$ boys $^{30}$ and for girls in India $(47 \%),{ }^{30}$ compared to the expected $2.27 \%$.

Thinness (BMI-for-age $\leq-2 \mathrm{SD}$ ) was also most severe in Chin State, among the studied girls, $31 \%$ and boys, $44 \%,{ }^{2}$ but high levels of thinness were also reported from Pakistan, $10 \%$ among both girls and boys. ${ }^{25}$ The lowest values found for these variables were from Japan among girls and boys with $3 \%$ and $4 \%$, respectively, ${ }^{31}$ and from Taiwan with $3 \%$ and $2 \%$, respectively. ${ }^{31}$

\section{Methodological considerations}

Data were collected as part of an educational and support programme from hard-to-reach villages and remote areas with, at many times, no real roads. The fieldworkers were educated theoretically and practically to collect the data, since the researchers were not allowed to enter the area due to political restrictions. To strengthen the data quality, three seminars were held outside the data collection sites, with researchers, fieldworkers and local leaders, where every measurement was discussed in depth.
General conclusions must be drawn with caution since the CCP children included were a select group of underprivileged children included in an educational and support programme. Owing to the local political situation, the CCS sample of ordinary children was small $(n=81)$; however, it showed a similar growth pattern that supports the CCP result.

Whether this reflects real genetic differences in linear growth and development rather than environmental influences, like a problematic nutritional situation, ${ }^{32}$ remains to be explored. Influencing factors, not studied, may be an insufficient infrastructure with lack of clean water, food, roads, etc.

One possible study limitation could be the language situation. The questionnaire was given in Burmese and English. All local leaders and fieldworkers involved in the data collection spoke English, not always fluently, but the local citizens did not. A few questionnaires were translated into a local language, which may have compromised the quality of the data. It was not back-and-forth translated, which would have been the optimal procedure. However, the trained fieldworkers who performed the data collection and also registered the information had good knowledge of the questionnaire, the local languages and the local situation.

The findings cannot be related to the basic population in Chin State, due to the uncertainty of these numbers, as stated in an Editorial in The Lancet 2012: "Burma has one of the worst health indicators in the world", and "Population estimates should be treated with caution 
because of the difficulty of collecting accurate birth data". 33

Illuminating the situation of these underprivileged children may serve as a basis for future interventional studies and for directed support to children in this area in order to improve their situation. The children involved in this study received support from our larger CDRS programme.

Acknowledgements The authors are deeply thankful to the local administrators and fieldworkers who collected all the data in Chin State and to the CDRS. The authors are also thankful for statistical advice from two professors in biostatistics, Elisabeth Svensson and Sune Karlsson, at the University of Örebro, Sweden.

Funding Örebro University, Sweden provided funding for equipment and local travel.

Competing interests None declared.

Provenance and peer review Not commissioned; externally peer reviewed.

Data sharing statement No additional data are available.

Open Access This is an Open Access article distributed in accordance with the Creative Commons Attribution Non Commercial (CC BY-NC 4.0) license, which permits others to distribute, remix, adapt, build upon this work noncommercially, and license their derivative works on different terms, provided the original work is properly cited and the use is non-commercial. See: http:// creativecommons.org/licenses/by-nc/4.0/

\section{REFERENCES}

1. Stevens GA, Finucane MM, Paciorek CJ, et al. Trends in mild, moderate, and severe stunting and underweight, and progress towards MDG 1 in 141 developing countries: a systematic analysis of population representative data. Lancet 2012;380:824-34.

2. Best C, Neufingerl N, van Geel L, et al. The nutritional status of school-aged children: why should we care? Food Nutr Bull 2010;31:400-17.

3. Jukes M. Impact of early childhood health and nutrition on access to education in developing countries. Paediatr Child Health 2007; 17:485-91.

4. Link BG, Phelan JC. Understanding sociodemographic differences in health-the role of fundamental social causes. Am J Public Health 1996;86:471-3.

5. Walker SP, Grantham-Mcgregor SM, Powell CA, et al. Effects of growth restriction in early childhood on growth, IQ, and cognition at age 11 to 12 years and the benefits of nutritional supplementation and psychosocial stimulation. J Pediatr 2000;137:36-41.

6. WHO Multicentre Growth Reference Study Group. Relationship between physical growth and motor development in the WHO Child Growth Standards. Acta Paediatr Suppl 2006;450:96-101.

7. Sollom R, Richards AK, Parmar P, et al. Health and human rights in Chin State, Western Burma: a population-based assessment using multistaged household cluster sampling. PLoS Med 2011;8: e1001007.

8. Rannan-Eliya RP, Hossain SM, Anuranga C, et al. Trends and determinants of childhood stunting and underweight in Sri Lanka. Ceylon Med J 2013;58:10-8.

9. de Onis M, Wijnhoven TM, Onyango AW. Worldwide practices in child growth monitoring. J Pediatr 2004;144:461-5.
10. (MGRS) WMGRSG. WHO Child Growth Standards based on length/ height, weight and age. Acta paediatr Suppl 2006;450:76-85.

11. Organization WMGRSGGWH. WHO Child Growth Standards: Length/height-for-age, weight-for-age, weight-for-length weight-for-height and body mass index-for-age: Methods and development. 2006.

12. Onyango AW, de Onis M, Caroli M, et al. Field-testing the WHO child growth standards in four countries. J Nutr 2007;137:149-52.

13. de Onis M, Onyango A, Borghi E, et al. Worldwide implementation of the WHO Child Growth Standards. Public Health Nutr 2012;15:1603-10.

14. World Health Organization. Growth reference data for 5-19 years (accessed 23 Nov 2014). http://www.who.int/growthref/en/

15. Altman DG. Practical statistics for medical research. London: Chapman \& Hall/CRC, 1997

16. World Health Organization. Nutrition Landscape Information System (NLIS) Country Profile Indicators. Interpretation Guide. 2010.

17. de Onis M, Dasgupta P, Saha S, et al. The National Center for Health Statistics reference and the growth of Indian adolescent boys. Am J Clin Nutr 2001;74:248-53.

18. de Onis M, Onyango AW, Borghi E, et al. Comparison of the World Health Organization (WHO) Child Growth Standards and the National Center for Health Statistics/WHO international growth reference: implications for child health programmes. Public Health Nutr 2006;9:942-7.

19. de Onis M, Onyango AW, Borghi E, et al. Development of a WHO growth reference for school-aged children and adolescents. Bull World Health Organ 2007;85:660-7.

20. Walton E, Allen S. Malnutrition in developing countries. Paediatr Child Health 2011;21:418-24.

21. Chowdhury SD, Chakraborty T, Ghosh T. Prevalence of undernutrition in Santal children of Puruliya district, West Bengal. Indian Pediatr 2008;45:43-6.

22. Dutta A, Pant K, Puthia R, et al. Prevalence of undernutrition among children in the Garhwal Himalayas. Food Nutr Bull 2009;30: $77-81$

23. Mitra M, Kumar PV, Chakrabarty S, et al. Nutritional status of Kamar tribal children in Chhattisgarh. Indian J Pediatr 2007;74 381-4.

24. Mondal N, Sen J. Prevalence of undernutrition among children (5-12 years) belonging to three communities residing in a similar habitat in North Bengal, India. Ann Hum Biol 2010;37:198-216.

25. Mushtaq MU, Gull S, Khurshid U, et al. Prevalence and socio-demographic correlates of stunting and thinness among Pakistani primary school children. BMC Public Health 2011;11:790.

26. Mushtaq MU, Gull S, Mushtaq K, et al. Height, weight and BMI percentiles and nutritional status relative to the international growth references among Pakistani school-aged children. BMC Pediatr 2012:12:31.

27. Wang X, Höjer B, Guo S, et al. Stunting and 'overweight' in the WHO Child Growth Standards-malnutrition among children in a poor area of China. Public Health Nutr 2009;12:1991-8.

28. Hoffman DJ, Lee SK. The prevalence of wasting, but not stunting, has improved in the Democratic People's Republic of Korea. J Nutr 2005;135:452-6.

29. Bisai S, Mallick C. Prevalence of undernutrition among Kora-Mudi children aged 2-13 years in Paschim Medinipur District, West Bengal, India. World J Pediatr 2011;7:31-6.

30. Pasricha SR, Biggs BA. Undernutrition among children in South and South-East Asia. J Paediatr Child Health 2010;46:497-503.

31. Mak KK, Tan SH. Underweight problems in Asian children and adolescents. Eur J Pediatr 2012:171:779-85.

32. Butte NF, Garza C, de Onis M. Evaluation of the feasibility of international growth standards for school-aged children and adolescents. J Nutr 2007:137:153-7.

33. [No authors listed]. Burma: Health and transition. Lancet 2012;379:2313. 